\title{
Implementing of the COM-B Model in In-Service Training of Civil Servants as a Prerequisite for Effective Public Governance
}

\author{
Andriy G. Rozskazov ${ }^{1}$ \\ Yuliia O. Chaliuk ${ }^{2}$ \\ Viktoriia O. Anishchenko3 \\ Iryna Smal ${ }^{4}$ \\ Olena Matviichuk 5
}

${ }^{1}$ Assoc. Professor, Department of State Service, Administration and Management, Institute of Continuing Education and Distance Study,

Luhansk Taras Shevchenko National University, Starobilsk, Ukraine

${ }^{2}$ Assoc. Professor, Department of Sociology, Personnel Management, Sociology and Psychology Faculty,

Kyiv National Economic University named after Vadym Hetman, Kyiv, Ukraine

3 Professor, Department of Pedagogy and Humanitarian Sciences,

Academy of the State Penitentiary Service, Chernihiv, Ukraine

${ }^{4}$ Assoc. Professor, Department of Theory, State and Law and Philosophy,

Faculty of Law, Private Higher Educational Establishment "Academician Stepan Demianchuk

International University of Economics and Humanities", Rivne, Ukraine

${ }^{5}$ Head of the Department of General Theoretical Legal Disciplines,

Rivne Institute of Kyiv University of Law of the National Academy of Sciences of Ukraine, Rivne, Ukraine

DOI: https://doi.org/10.36941/ajis-2021-0o8o

\section{Abstract}

The purpose of the study was to identify how the reshaped COM-B model-based refresher courses for the civil servants influences the sampled students' intrinsic motives of performing their job functions and to identify how the students perceived the upgraded course that used the COM-B model. The study combined an exploratory design that was used in the baseline phase and a one-group-based pre-test-post-test design that was used in the quasi-experimental intervention. It used the data collection tools such as the baseline study online survey, the Intrinsic Motivation Inventory, the HR departments' assessment reports, the Awareness of Public Service Legislation Test, and the focus group survey questionnaire. The IBM SPSS Statistics (25.0.0.1) was used to process the data. The reshaped COM- $B$ model-based refresher courses for the civil servants are capable to influence positively the sampled students' intrinsic motives of performing their job functions. The use of the COM-B model provides a triple influence on the intrinsic motives of the civil servants, changes their behaviour, and increases their work performance level. It was found that respondents benefited from the challenges of performing different roles in the civil service that they experienced in the course. They upgraded their professional knowledge. The extrinsic motivation factors dominate the civil servants' motivation and the management of public institutions underperforms in identifying and using the appropriate solutions to stimulate the inner motivation in civil servants for higher standards of their work performance. The civil servants should receive yearly training using more student-focused methods, the cognition function development-aimed, and function-through-context-based.

Keywords: COM-B model, in-service training of civil servants, public governance, intrinsic motives 


\section{Introduction}

The in-service training of civil servants is gradually paid more attention in terms of influencing their behaviour and motivation as these are seen as a prerequisite for effective public governance (Orliv, 2016; Orliv, 2019). The Capability, Opportunity, and Motivation Behaviour (COM-B) model is a recent behaviour change model that relies on three pillars such as capabilities $(\mathrm{C})$, opportunities $(\mathrm{O})$, and motivation (M) (West \& Michie, 2020). Michie, Stralen \& West (2011) explain that behaviour change occurs due to controlled organisation of interaction between those three dimensions such as Cs-OsMs. It was found that the in-service training system of civil servants relies on influencing their competence structure and their intrinsic and extrinsic motives of performing their job functions so that they were fulfilled up to standard. However, the evidence proves that even though the civil servants' competence level is sufficient, it does not always ensure that they can be fully functional in public governance because of the inadequacy of certain intrinsic motives (Druskiene \& Sharkunaite, 2018).

\subsection{Literature review}

The review of the relevant literature found that in contrast to the private sector, employees of the public sector are under-motivated financially and it is very important that the feeling of accomplishment could be influenced more intensively (Andersen et al., 2020). Though the public service motivation is seen by the community as the self-stimulated desire of the civil servant to create an environment of wellbeing, the public-interest-commitment is gradually decreasing in both the civil service applicants and employees (Druskiene \& Sharkunaite, 2018; Leisink et al., 2018). Perry (2015) along with Thompson \& Christensen (2018) suggest stimulating the feeling of importance in the civil servants in terms of their contribution to organisational goals increases their job commitment which results in increased governance effectiveness. The COM-B model was designed to influence the very intrinsic motivation which is then manifested in the civil servant's behavior. It relies on the Behaviour Change Wheel (BCW) involving evidence-based practice (Michie et al., 2011). The model provides information about the relationships of the components such as physical and psychological capability $(C)$ that can be addressed through the use of social and physical opportunities $(\mathrm{O})$ based on motivators $(\mathrm{M})$. It reveals what (which) behaviour patterns should be targeted through the intervention (Jatau, 2019).

Therefore, the purpose of the study was 1) to identify how the reshaped COM-B model-based refresher courses for the civil servants influences the sampled students' intrinsic motives of performing their job functions; and 2) to identify the students' perceptions of the upgraded course that uses the COM-B model.

\section{Methods and Materials}

This study employed the research methods recommended for exploratory and quasi-experimental studies in sociology and education (Chapman et al., 2005; Cohen et al., 2017). The data from the baseline study was drawn from the survey. The data for the pre-test and post-test measurements were yielded for the Intrinsic Motivation Inventory (IMI) (6 scales-based) (CSDT, n.d.) that was modified to fit the context of the public service servants and from HR department-administered performance assessment based on criteria suggested in Resolution \#640 of the Cabinet of Ministers of Ukraine (2017). The Test in Awareness of Public Service Legislation (available at https://nads.gov.ua/testuvannya-kandidativna-posadi-derzhavnoyi-sluzhbi/perelik-testovih-pitan-na-znannya-zakonodavstva-z-variantamividpovidej) that is approved by the National Agency of Ukraine for Civil Service was adapted and translated to fir the purpose of the study. The intervention lasted 16 weeks period from November 2019 to March 2020 and involved the participants of the in-service (refresher) training course run at the Institute of In-service Training of Civil Servants and local government officials of I-IV categories (IITCS, Kyiv, Ukraine) representing government authorities and local government bodies. The refresher course syllabus was reshaped to use the COM-B model. The course was delivered in English. For this reason, 
the sampled students were supposed to have a B1-B2 level (CEFR) of English and they took the Online English Level Test available at https://learnenglish.britishcouncil.org/online-english-level-test, to prove it. The representatives of the HR departments from the National Agency of Ukraine for Civil Service were involved as the guest speakers and supervisors for the participants of the refresher course.

\section{$2.1 \quad$ Research design}

The study combined an exploratory design that was used in the baseline phase and a one-group-based pre-test-post-test design that was used in the quasi-experimental intervention (see Figure 1).
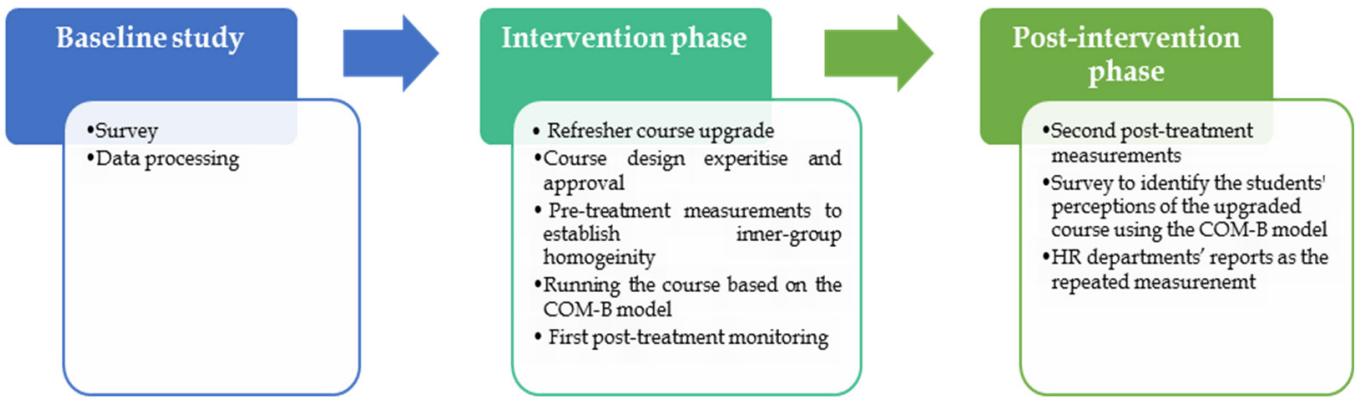

Figure 1: The Phases of the study

The baseline study was carried out to identify whether the intervention in the in-service training of civil servants based on the COM-B model is feasible. It relied on the survey that was intended to specify the motivational factors that influence the civil servants' motivation at the workplace and the level of their performance. That list included factors as follows: benefits and privileges, power and money, career promotion opportunities and career ambitions, ambitions to play the important role in the society, job functions, independence level, job environment, superior's management style, in-service training opportunities, social security package, and performance appraisal results. The randomly selected respondents were given access to the Google Form-based survey questionnaire and they were estimated to evaluate the extent of the importance of the specified factors for their job motivation and performance. The baseline study found that extrinsic motives were the most important factors the civil servants' motivation at the workplace and the level of their performance which indicated that the intervention to influence the intrinsic motives of the civil servants was feasible.

The quasi-experimental intervention was based on the use of the COM-B model to the delivery of the refresher course. The intervention was proceeded by the measurements of the participants' English language level, sampled students' interest/enjoyment of their job functions, perceived competence in governance, effort, value/usefulness, felt pressure and tension, and perceived choice. The Test in Awareness of Public Service Legislation was used to elaborate on the assessment of participants' competence.

\subsection{Description of the conceptual framework of the model}

The delivery of every class and every module of the refresher courses for the civil servants was reshaped to fit the COM-B model (see Figure 2). The course was taught in English and it was of a 3-Credit (ECTS) and 4 module structure. It included four modules such as "Effective Governance", "Anti-corruption policy", "Decentralisation", and "Economic development". These were based on evidencebased practices. Table 1 provides information about the topics studied in each module. 

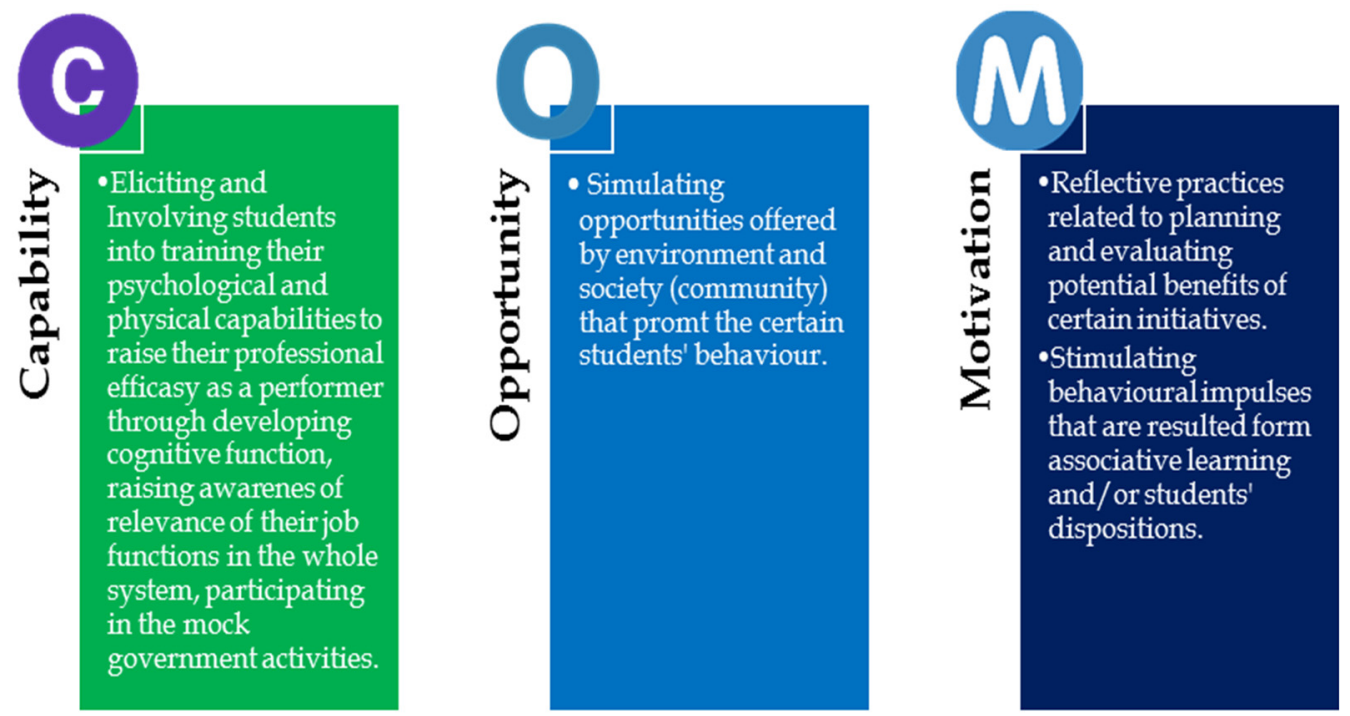

Figure 2: COM-B model of the delivery of the refresher courses to the civil servants

Table 1: Civil Servants Refresher Course Structure

\begin{tabular}{|c|c|c|}
\hline Module & Topic & Hours \\
\hline \multirow{5}{*}{$\begin{array}{l}\text { Effective } \\
\text { Governance }\end{array}$} & 1. Sociodemographic factors of risk management and crisis management. & 6 \\
\hline & 2. Adequate civil servants' civic competencies. & 6 \\
\hline & 3. Community welfare-purpose strategic management and project management. & 6 \\
\hline & 4. Political leadership, conflictology, and elitology in PR communication. & 6 \\
\hline & 5. Self-management of a manager. & 6 \\
\hline \multirow{2}{*}{$\begin{array}{l}\text { Anti-corruption } \\
\text { policy }\end{array}$} & 6. Prevention and counteraction of corruption in government bodies. & 8 \\
\hline & 7. Ethics in public administration. Conflict of interest prevention. & 8 \\
\hline \multirow{3}{*}{ Decentralisation } & $\begin{array}{l}\text { 8. Decentralisation of power: delimitation of powers of executive bodies and local self- } \\
\text { government bodies. }\end{array}$ & 8 \\
\hline & 9. Resource maintenance for local development. & 6 \\
\hline & 10. Budget decentralisation. Local budgeting and accountability to citizens. & 8 \\
\hline \multirow{4}{*}{$\begin{array}{l}\text { Economic } \\
\text { development }\end{array}$} & 11. Global perspective of local development strategies. & 6 \\
\hline & 12. Economic cooperation with the European Union. Eurozone. & 6 \\
\hline & 13. Public administration in the field of investment and innovation. & 6 \\
\hline & $\begin{array}{l}\text { 14. State regional policy and economic development of territories. Territorial } \\
\text { development forecasting and planning. }\end{array}$ & 6 \\
\hline
\end{tabular}

The 'capability' component of the course was delivered online while the other two were delivered offline. Each topic-based series of classes used formal and informal assessment approaches and were finished by the feedback of the experts aimed at strengthening the motivation of the students. These feedback classes were run by visiting speakers and were organised as a question-answer session or round-table discussion session or mind session.

\subsection{Sampling}

Random sampling was used to administer the baseline study online survey to 179 civil servants. A voluntary response sampling technique was utilised to form the experimental group (EG) draw from a 
readily accessible population. Due to the fact that the sampled individuals did the same course, they were considered to be mutually homogeneous. Twenty-seven volunteers doing the refresher and upgrade course for the civil servants run by the Institute of In-service Training of Civil Servants and local government officials of I-IV categories (IITCS, Kyiv, Ukraine) representing government authorities and local government bodies were hired to form the EG. Their demographic features are outlined in Table 2.

Table 2: The demographic features of the EG participants $(\boldsymbol{n}=\mathbf{2 7})$

\begin{tabular}{|c|c|c|c|c|c|c|c|}
\hline \multicolumn{3}{|l|}{ Feature } & $n=27$ & $\%$ & $S S$ & $S E$ & $p$ \\
\hline \multirow{2}{*}{ Gender } & \multicolumn{2}{|l|}{ Males } & 12 & 44.44 & \multirow{2}{*}{ n.d. } & \multirow{2}{*}{ n.d. } & \multirow{2}{*}{$<0.001$} \\
\hline & \multicolumn{2}{|l|}{ Females } & 15 & 55.56 & & & \\
\hline \multirow{8}{*}{ Age } & Males & $25-34$ & 1 & 08.33 & \multirow{4}{*}{10.00} & \multirow{4}{*}{0.91287} & \multirow{4}{*}{0.176} \\
\hline & & $35-45$ & 5 & 41.67 & & & \\
\hline & & 46-55 & 4 & 33.34 & & & \\
\hline & & $55-65$ & 2 & 16.66 & & & \\
\hline & Females & $25-34$ & 3 & 20.00 & & & \\
\hline & & $35-45$ & 7 & 46.66 & 18.75 & 1.2500 & 0.319 \\
\hline & & 46-55 & 4 & 26.66 & & & 0.319 \\
\hline & & $55-65$ & 1 & 06.68 & & & \\
\hline & Central A & ion & 3 & 11.11 & & & \\
\hline Administration affiliation & Territoria & ration & 13 & 48.14 & 56.00 & 3.05505 & 0.419 \\
\hline & Local adn & & 11 & 40.75 & & & \\
\hline & Economy & & 9 & 33.33 & & & \\
\hline & Legislatio & & 2 & 07.40 & & & \\
\hline & Educatiol & & 3 & 11.11 & & & \\
\hline Public service branch & Medicine & & 6 & 22.23 & 42.86 & 1.01015 & 0.328 \\
\hline & Sport & & 2 & 07.41 & & & \\
\hline & Culture & & 2 & 07.41 & & & \\
\hline & Internati & & 3 & 11.11 & & & \\
\hline
\end{tabular}

\subsection{Ethical considerations}

The informed consent to participate voluntarily in the course based on the COM-B model was obtained from the EG students. The confidential disclosure agreement was signed by all the parties involved in the experiment prior to it. The EG students provided written consent to the team of the researchers to use the research output data and the signees' personal details only under the permission of the signees.

\subsection{Instruments}

The baseline study online survey, the Intrinsic Motivation Inventory (IMI) (6 scales-based), the HR departments' assessment reports (HRAR), the Awareness of Public Service Legislation Test (APSLT), and the focus group survey questionnaire were research instruments to collect data. The IBM SPSS Statistics (25.0.0.1) was used to process the data.

The baseline study online survey was administered in the Ukrainian language. The list of 11 factors such as benefits and privileges, power and money, career promotion opportunities and career ambitions, ambitions to play the important role in the society, job functions, independence level, job environment, superior's management style, in-service training opportunities, social security package, and performance appraisal results were specified to play the main role in their work motivation and performance. Several sources were used to make a list of the factors (Ciobanu \& Androniceanu, 2015; Druskiene \& Sharkunaite 2018; HRLiga, 2019). The list was validated by four HR volunteer managers. The 5-point Likert importance scale that used the values from $1=$ Not at all important up to $5=$ Extremely 
important was used by the respondents to evaluate each factor.

The Intrinsic Motivation Inventory (IMI) (6 scales-based) was chosen because it is flexible as its items can be modified to suit the specific area and the scales have been proved to show good coherence in factor analytics which has been stable across a variety of settings, applications, and conditions. The factor loading of at least 0.6 has been commonly found as criteria for inclusion of items on subscales, while the cross-loadings above 0.4 have not. The scales assess the participants' interest/enjoyment, perceived competence, effort, value/usefulness, felt pressure and tension, and perceived choice.

The HR departments' reports on the EG students' performance in the pre-intervention phase and as the repeated measurement in the post-intervention phase were provided in the Ukrainian language, then translated and text part was analysed using the Voyant Tools which are accessed through the link: https://voyant-tools.org/. These tools are commonly used in studies (Boyle \& Hall, 2016).

The Test in Awareness of Public Service Legislation was originally designed for the intervention. The methods of Differential Item Functioning (DIF) analyses and Differential Test Functioning (DTF) analyses were used to check the validity and reliability of the test. The Lord's Chi-square DIF method was utilised to detect uniform (UDIF) and non-uniform DIF (NUDIF) items. The Mantel-Haenszel/LiuAgresti (MH-LA) method was used to calculate DTF (Guo, Robin \& Dorans, 2017; Hunter, 2014).

The focus group survey questionnaire ( $n=9$ respondents)

The questionnaire was designed and administered as recommended by Krueger \& Casey (2015). It consisted of 4 open-ended questions whose content and discourse were validated by the research team members. The surveys lasted 15-20 minutes each, they were recorded and transcribed. The Voyant Tools (VTs) were used to process the text corpus of responses to identify the keywords/concepts (Sinclair \& Rockwell, 2015).

1. What do you think of the reshaped refresher course delivery?

2. What benefits did you experience due to the course? Give examples.

3. What experiences occurred in the course did you consider to be negative? Why?

4. How would you change the course so that it could bring more benefits to the students and public authorities? Suggest your reasoning.

\section{Results}

The results obtained for the study proved that the reshaped COM-B model-based refresher courses for the civil servants positively influence the sampled students' intrinsic motives of performing their job functions and the upgraded course using the COM-B model is positively perceived by the students. The quantitative and qualitative input and output data are presented below.

\subsection{Results of the baseline study survey}

As can be seen in Figure 3, while the civil servants indicated that they were mostly motivated by the extrinsic factors such as superior's management style, work environment, social security package, inservice training opportunities, they rated such factors as ambitions to play the important role in the society, job functions, independence level (responsibility level) the lowest. The result suggested that the development of a system to influence the civil servants' behaviour and motivation was feasible. 


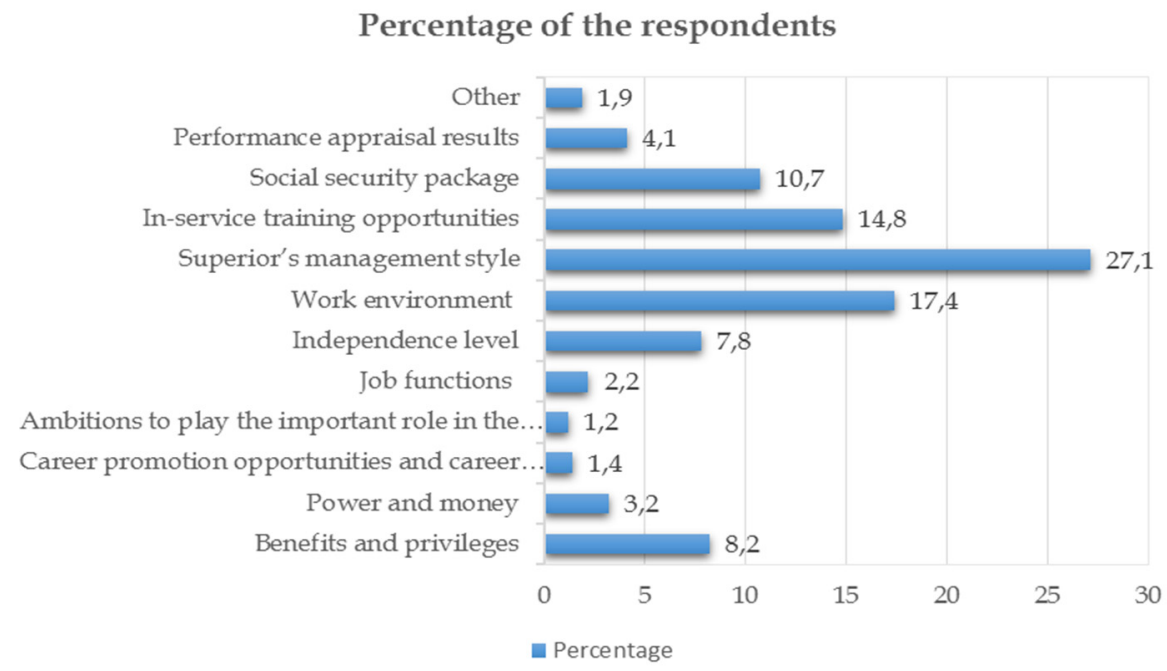

Figure 3: Factors rated by the respondents as important motivators at the workplace and the level of performance, $\%$

\subsection{The intervention phase results}

The results of the pre-test-post-test measurements suggest that the students raised their awareness in their occupation along with psychological and physical capabilities to apply the knowledge. The EG students improved their intrinsic motivation through gaining a better vision of the opportunities to bring value to the community and to gain respect in it. The results of the measurements are presented in Table 3.

Table 3: Results obtained through IMI, HRAR, APSLT (10o-point scale) $(\boldsymbol{n}=\mathbf{2 7})$

\begin{tabular}{|l|c|c|c|c|c|c|}
\hline \multirow{2}{*}{ Data source } & \multicolumn{2}{|c|}{ Pre-test } & \multicolumn{2}{c|}{ Post-test } & \multirow{2}{*}{$t$-value } & \multirow{2}{*}{$p-$ value } \\
\cline { 2 - 6 } & Mean & SS & Mean & SS & & .004024 \\
\hline IMI & 62.86 & 400.86 & 75.71 & 289.43 & -3.17143 & .000139 \\
\hline HRAR & 71.43 & 183.71 & 87.14 & 220.86 & -5.06316 & $<.00001$ \\
\hline APSLT & 66.14 & 112.86 & 90.29 & 241.43 & -8.31259 & $<$ \\
\hline
\end{tabular}

Note: IMI = Intrinsic Motivation Inventory; HRAR = HR Departments' Assessment Report; APSLT $=$ Awareness of Public Service Legislation Test.

The measurements showed a rise in the EG students' intrinsic motivation in the post-test phase $(M=75.71 ; t(27)=-3.17143, p=.004024)$. There was an increase in job performance in this phase $(M=87.14$, $t(27)=-5.06316, p=.000139)$. The public service legislation awareness also improved $(M=90.29$ in the post-test phase compared to $\mathrm{M}=66.14$ before intervention; $t(27)=-8.31259, p=<.00001)$. The result is significant at $p<.05$.

\subsection{Repeated measurement of civil servants' performance, six months later}

In this phase, the HR departments' reports on the EG students' performance were translated into English, and the text part was analysed using the Voyant Tools. The result of the text corpus analysis 
is presented in Figure 4. The analysis found that the most frequently used words were as follows: motivated, performance, better, deadlines, efficient. The correlations between the words are presented in Table 4 .

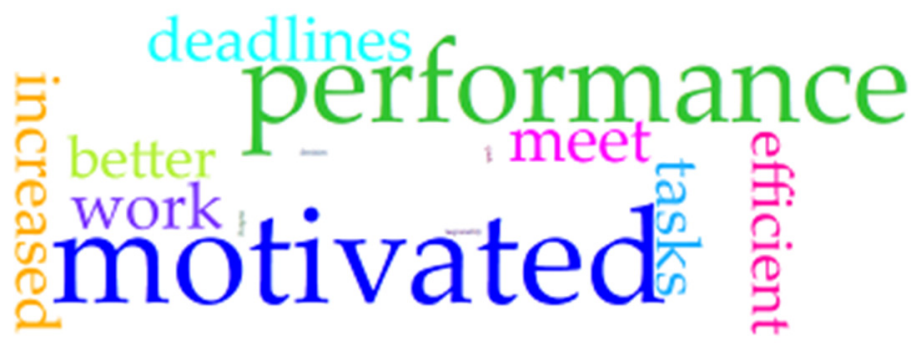

Figure 4: HR departments' reports on the EG students' performance

Table 4: The correlations between the words

\begin{tabular}{|c|c|c|c|c|}
\hline Term 1 & & Term 2 & Correlation & Significance \\
\hline motivated & $\leftarrow \rightarrow$ & efficient & 1 & 0.012 \\
\hline increased & $\leftarrow \rightarrow$ & efficient & 1 & 0.024 \\
\hline better & $\leftarrow \rightarrow$ & deadlines & 0.769 & 0.035 \\
\hline better & $\leftarrow \rightarrow$ & motivated & 0.731 & 0.039 \\
\hline meet & $\leftarrow \rightarrow$ & tasks & 0.726 & 0.045 \\
\hline efficient & $\leftarrow \rightarrow$ & work & 0.711 & 0.047 \\
\hline
\end{tabular}

Note: If a correlation of values approaches +1 , it means that the terms rise and drop together (positive correlation). A significance of .05 and less indicates a strong correlation.

The correlation values in Table 4 suggest that the HR managers paid emphasis on the high level of motivation which was related to the increased efficiency, and meeting deadlines with the tasks. The results obtained six weeks later imply that former refresher course participants were more motivated at the workplace and showed a higher level of performance due to the intervention.

The results of the focus group survey ( $n=9$ respondents)

Question 1. Having analysed the text corpus of the surveyed students, it was found that benefits, job, engaging, interesting, specialism were the five most frequently used words (Figure 5).

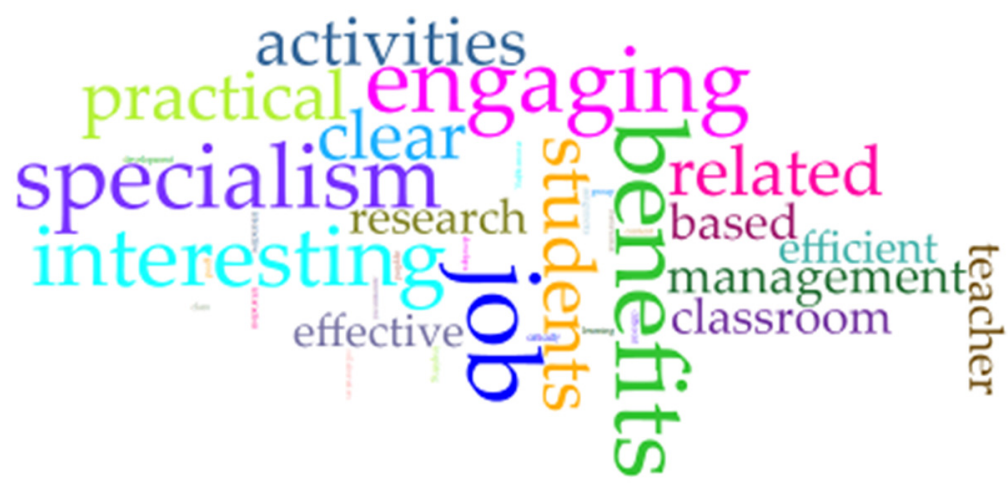

Figure 5: The most frequently used words in the text corpus of the survey responses 
In Figure 6, the high frequency (9 out of 10) is observed between the terms "engaging", "practical", "specialism", and "benefits". The highest correlation (10 in 10) is found between the words "specialism", "benefits" and "engaging".

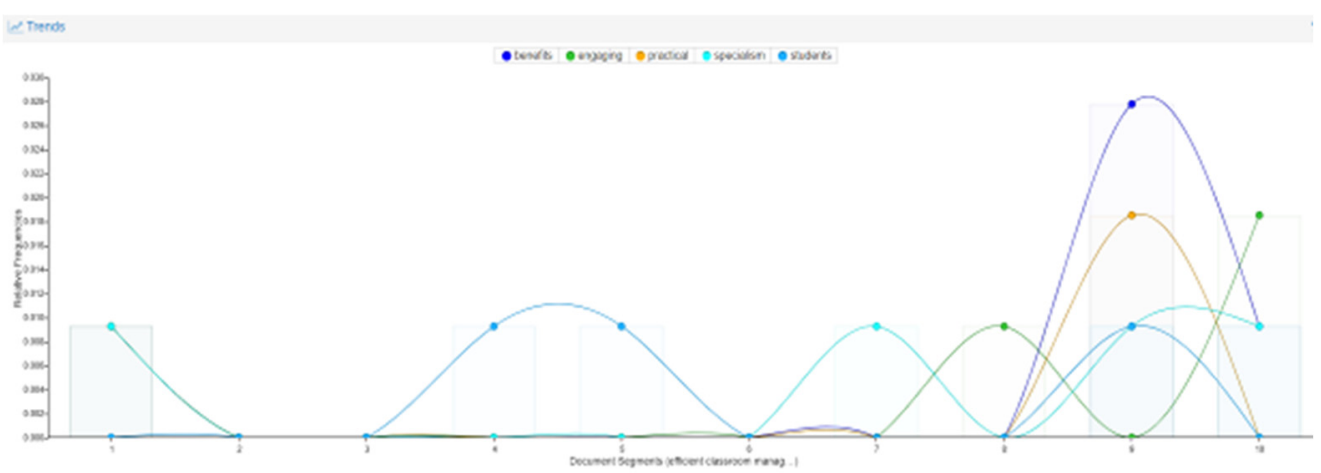

Figure 6: Distribution trend of the terms of the text corpus of the responses

Question 2. The EG participants reported that they experienced challenges of performing different roles in the civil service. They upgraded their professional knowledge. They got the answers to their questions from the experts.

Question 3. The respondents confessed that sometimes they experienced too much pressure and too strict deadlines. Three students confessed that they sometimes felt embarrassed for underperformance in the home assignments.

Question 4. The respondents proposed to invite the speakers from the European Union and to use more technology.

\subsection{Limitations}

The limitations of this study can be the involvement of one institution, one group, and the sample size. These can lead to a dispute concerning the significance and representatives of the results.

\section{Discussion}

The study addressed questions such as how the reshaped COM-B model-based refresher courses for the civil servants influenced the sampled students' intrinsic motives of performing their job functions and how the students perceived the upgraded course that had used the COM-B model. The novelty of the study lies in the delivery approaches such as first, the use of the English language as a learning medium, and second, the use of the COM-B model to provide a triple influence on the intrinsic motives of the civil servants to change their behaviour and increase their work performance level.

The study found that the reshaped COM-B model-based refresher courses for the civil servants influenced the sampled students' intrinsic motives for performing their job functions. Furthermore, the courses were found to raise the level of work performance after the course was completed. The students reported that the course was engaging and practically valuable for their job, from a broad perspective.

The pre-test post-test results of measurements showed that there was a rise in the EG students' intrinsic motivation in the post-test phase $(M=75.71 ; t(27)=-3.17143, p=.004024)$. There was an increase in job performance in this phase $(M=87.14, t(27)=-5.06316, p=.000139)$. The public service legislation awareness also improved $(M=90.29$ in the post-test phase compared to $M=66.14$ before intervention; $t(27)=-8.31259, p=<.00001)$. The results of the repeated measurement of civil servants' performance that 
was conducted six months later supported the above findings.

The analysis of HR departments' reports on the EG students' performance found that the most frequently used words were as follows: motivated, performance, better, deadlines, efficient. This suggested that the HR managers paid emphasis on the high level of motivation which was related to the increased efficiency, and meeting deadlines with the tasks. The results implied that former refresher course participants were more motivated at the workplace and showed a higher level of performance due to the intervention.

The focus group respondents reported that appreciated the challenges of performing different roles in the civil service that they experienced in the course. They upgraded their professional knowledge. They got the answers to their questions from the experts.

The obtained results go in line with the relevant research. It aligns with a state policy contemplating the updating of the system of the in-service training of the civil servants in Ukraine (Governmental portal, 2018). It attempted to address the limitations of the in-service training system such as the use of the specialism-related English language and lack of focus on students' intrinsic motives. The findings of the study agree with Ciobanu \& Androniceanu (2015) who stated that the management of public institutions underperforms in identifying and using the appropriate solutions to motivate civil servants for higher standards of their work performance. Moreover, the study aligns with their conclusions concerning the fact that extrinsic motivation factors dominate the civil servants' motivation.

The study supports the findings of Tessema et al. (2007) who reveal that the refresher in-service course should be a 3-credit one (ECTS, 90-10o hours) and the civil servants should receive training yearly. The training should include $60 \%$ of work-related learning and psychological experiences and $40 \%$ of self-directed learning activities. The findings align with Sun (2019) who suggests that methods used in the in-service training for the civil servants should be more student-focused, the cognition function development-aimed, and function-through-context-based. The study supports the implications made by Druskiene \& Sharkunaite (2018) what claimed that it is not just idealistic motives that motivate the civil service but the balanced motivation system including monetary, moral, political, normative, and emotional stimuli. Further research is needed to identify the COM-B model that can be used at colleges and universities to train student civil service managers.

\section{Conclusion}

The reshaped COM-B model-based refresher courses for the civil servants are capable to influence positively the sampled students' intrinsic motives of performing their job functions. The use of the COM-B model provides a triple influence on the intrinsic motives of the civil servants, changes their behaviour, and increases their work performance level. It was found that respondents benefited from the challenges of performing different roles in the civil service that they experienced in the course. They upgraded their professional knowledge. They got the answers to their questions from the experts. The study added value to a state policy contemplating the updating of the system of the in-service training of the civil servants in Ukraine by addressing the limitations of the in-service training system such as the use of the specialism-related English language and lack of focus on students' intrinsic motives. The extrinsic motivation factors dominate the civil servants' motivation and the management of public institutions underperforms in identifying and using the appropriate solutions to stimulate the inner motivation in civil servants for higher standards of their work performance. The civil servants should receive yearly training of at 3-credits one (ECTS, 90-10o hours) including $60 \%$ of work-related learning and psychological experiences and $40 \%$ of self-directed learning activities and using more student-focused methods, the cognition function development-aimed and function-through-contextbased. 


\section{Acknowledgement}

We are grateful to the experts, visiting speakers, and management from the Institute of In-service Training of Civil Servants and local government officials of I-IV categories (Kyiv, Ukraine) for their assistance in reshaping the course design, updating its content and structure. We are also thankful to the participants who made this study a fruitful experience for all the parties who were involved.

\section{References}

Andersen, L. B., Jensen, U. T., \& Kjeldsen, A. M. (2020). 'Public service motivation and its implications for public service'. In H. Sullivan, H. Dickinson \& H. Henderson (Eds.), The Palgrave Handbook of the Public Servant. Cham: Palgrave Macmillan. https://doi.org/10.1007/978-3-030-03008-7_81-1

Boyle, M., \& Hall, C. (2016). Teaching don quixote in the digital age: Page and screen, visual and tactile. Hispania, 99(4), 6oo-614. https://doi.org/10.1353/hpn.2016.0106

Cabinet of Ministers of Ukraine. (2017). Resolution \#640 "On approval of the Standard procedure for evaluating the performance of civil servants". https://zakon.rada.gov.ua/laws/show/640-2017-\%Do\%BF\#Text

Centre for Self-Determination Theory (CSDT). (n. d.). Intrinsic Motivation Inventory - Complete Packet. https://selfdeterminationtheory.org/intrinsic-motivation-inventory/

Ciobanu, A., \& Androniceanu, A. (2015). Civil servants' motivation and work performance in Romanian public institutions. Procedia Economics and Finance, 30, 164-174. https://doi.org/10.1016/s2212-5671(15)o1280-o

Chapman, S., McNeill, P., \& Mcneill, P. (2005). 'Research methods in sociology'. In S. Chapman, P. McNeill \& P. Mcneill (Eds.), Research Methods. London: Routledge, https://doi.org/10.4324/97802034630oo

Cohen, L., Manion, L., \& Morrison, K. (2017). Research methods in education. New York: Routledge. https://books.google.com.ua/books/about/Research_Methods_in_Education.html?id=iaQ5DwAAQBAJ\&pri ntsec $=$ frontcover\&source $=\mathrm{kp} \_$read_button\&redir_esc $=\mathrm{y} \# \mathrm{v}=$ onepage\&q\&f=false

Governmental portal. (2018). Government improves the training of civil servants. Cabinet of Ministers of Ukraine. https://www.kmu.gov.ua/en/news/uryad-vdoskonalyuye-sistemu-navchannya-derzhavnih-sluzhbovciv

Guo, H., Robin, F., \& Dorans, N. (2017). Detecting item drift in large-scale testing. Journal of Educational Measurement, 54 (3), 265-284. https://doi.org/10.1111/jedm.12144

Druskiene, A., \& Sharkunaite, I. (2018). Motivational incentives of civil servants in Lithuanian municipalities. Public Policy \& Administration, 17(3), 344-37o. https://doi.org/10.5755/jo1.ppaa.17.3.21952

HRLiga. (2019). Motyvatsia i zaokhochennia derzhavnykh sluzhbovtsiv (Motivation and stimulation of the civil servants). https://hrliga.com/index.php?module=profession\&op=view\&id=1872

Hunter, C. (2014). A simulation study comparing two methods of evaluating differential test functioning (DTF) [Doctoral Dissertation, Repository for Georgia State University], Atlanta, GA. https://scholarworks.gsu.edu/cgi/viewcontent.cgi?article=1132\&context=eps_diss

Jatau, A. I., Peterson, G. M., Bereznicki, L., Dwan, C., Black, J. A., Bezabhe, W. M., \& Wimmer, B. C. (2019). Applying the capability, opportunity, and motivation behaviour model (COM-B) to guide the development of interventions to improve early detection of atrial fibrillation. Clinical Medicine Insights: Cardiology, 13, 1-8. https://doi.org/10.1177/1179546819885134

Krueger, R. A., \& Casey, M. A. (2015). Focus group: A practical guide for applied research (5 ${ }^{\text {th }}$ ed.). SAGE Publishing. https://doi.org/10.1002/9781119171386.ch2o

Leisink, P. L. M., Knies, E. \& Loon, N. (2018). Does public service motivation matter? A study of participation in various volunteering domains. International Public Management Journal, 1-21. https://doi.org/10.1080/10967494.2018.1428254

Michie, S., Stralen, M. M., \& West, R. (2011). The behaviour change wheel: A new method for characterising and designing behaviour change interventions. Implementation Science 6 (42), 1-11. https://doi.org/10.1186/17485908-6-42

Orliv, M. S. (2016). Development of an in-service training system for civil servants and local self-government officials in Ukraine using the incrementalist model. Bulletin of the NAPA under the President of Ukraine, 2, 139-145. http://visnyk.academy.gov.ua/pages/dop/54/files/7c5595e3-564e-42f5-982c-10f8f22cc4d3.pdf

Orliv, M. S. (2019). In-service training for civil servants in the context of ensuring the sustainable development of Ukraine (archetypal approach). Public Management, 1, 336-345. https://doi.org/10.32689/2617-2224-2019-18-3336-345 
Perry, J. L. (2015). 'Civil service systems and public service motivation'. In van der Meer F. M., Raadschelders J. C. N. \& Toonen T. A. J. (Eds.), Comparative Civil Service Systems in the $21^{\text {st }}$ Century. London: Palgrave Macmillan. https://doi.org/10.1057/9781137491459_12

Sinclair, S., \& Rockwell, G. (2015). 'Text analysis and visualisation: Making meaning count'. In S. Schreibman, R. Siemens \& J. Unsworth (Eds.), A New Companion to Digital Humanities (pp. 274-290). Malden, MA: Wiley Blackwell. https://doi.org/10.1002/9781118680605.ch19

Sun, Y. (2019). 'Ways and methods to improve the training of civil servants'. Proceedings for the $4^{\text {th }}$ International Conference on Education Science and Development, 1-7. https://doi.org/10.12783/dtssehs/icesd2019/28080

Tessema, M. T., Soeters, J. L., Groot, G., \& Tesfaselassie, M. F. (2007). Managing civil service training institutions: what lessons can countries learn from Singapore? International Journal of Human Resources Development and Management, 7(3). https://doi.org/10.1504/ijhrdm.2007.017136

Thompson, J. A., \& Christensen, R. K. (2018). Bridging the public service motivation and calling literatures. Public Administration Review, 78(3), 444-456. https://doi.org/10.111//puar.12913

West, R., \& Michie, S. (2020). A brief introduction to the COM-B model of behaviour and the PRIME Theory of motivation. Oeios. https://www.qeios.com/read/WWo4E6.2 